\title{
EPICTETO, DIATRIBE 1.28 - PORQUE É PRECISO NÃO SE IRRITAR COM OS SERES HUMANOS, E QUAIS SÃO AS COISAS PEQUENAS E GRANDES ENTRE ELES
}

\section{ALDO LOPES DINUCCI}

Doutor em Filosofia. Professor da Universidade Federal de Sergipe e do Programa de Pós-Graduação em Filosofia desta universidade. E-mail: aldodinucci@yahoo.com.br

Tradução submetida em Fevereiro/2016 e aceita em Julho/2016

\section{RESUMO}

Na presente diatribe, Epicteto trata da questão do princípio da ação para os estoicos: a opinião (dogma, hypolepsis). Assentimos a uma opinião por crermos ser ela o caso, por crermos ser ela verdadeira. Em outras palavras, por natureza tendemos a assentir àquilo que nos parece verdadeiro, a negar assentimento ao que nos parece falso e a suspender o juízo sobre as coisas que não nos parecem uma coisa ou outra.
Por esse princípio, não devemos nos irritar com os que erram, pois erram crendo estar acertando, quer dizer, dão assentimento a uma opinião ou crença que lhes parece verdadeira, mas que é, na verdade, falsa, dando exemplo disso Medéia.

PALAVRAS-CHAVE: Epicteto. Estoicismo. Diatribes.

\section{INTRODUÇÃO}

Epicteto, um dos grandes nomes do Estoicismo Imperial, entre os quais se incluem Sêneca, Musônio Rufo e Marco Aurélio, nasceu no ano 55, em Hierápolis, na Frígia, e morreu por volta de 135, em Nicópolis, antiga cidade localizada na entrada do Golfo Ambraciano, no Épiro. Filho de uma serva, recebeu um nome que era comumente dado a servos na Antiguidade e que significa "adquirido". Epicteto mesmo nada escreveu. Tal tarefa coube a Lúcio Flávio Arriano Xenofonte, cidadão romano de origem grega, que compilou (possivelmente com auxílio da taquigrafia) suas aulas em oito livros (As Diatribes de Epicteto), dos quais quatro sobrevivem, e constituiu o Encheirídion de Epicteto, um breviário de princípios morais epicteteanos.

Na presente diatribe, Epicteto trata da questão do princípio da ação para os estoicos (1.28.1): a opinião (dogma, hypolepsis). Assentimos a uma opinião por crermos ser ela o caso, por crermos ser ela verdadeira. Em outras palavras, por natureza tendemos a assentir àquilo que nos parece verdadeiro, a negar assentimento ao que nos parece falso e a suspender o juízo sobre as coisas que não nos parecem uma coisa ou outra (1.28.2). Por esse princípio, não devemos nos irritar com os que erram, pois erram crendo estar acertando, quer dizer, dão assentimento a uma opinião ou crença que lhes parece verdadeira, mas que 
é, na verdade, falsa, dando exemplo disso Medéia (1.28.7-8).

Mais adiante (1.28.10), Epicteto reafirma o que disse sinteticamente, refletindo que, "para o homem, a medida de toda ação é o que se afigura", parafraseando o famoso dito de Protágoras. Para Epicteto, esse princípio que, como dissemos, fundamenta todas as ações humanas, deve nos servir de alerta e direcionar nossa atenção: pois se nossas ações são guiadas pelos nossos assentimentos, que, por sua vez, são dados ao que nos parece ser o caso, então nos é de primeira importância avaliar se o que nos parece ser o caso é realmente o caso, se o que nos parece verdadeiro é realmente verdadeiro. Sem isso, agiremos como os demais, seguindo o que nos parece o caso imediata e irrefletidamente e ao acaso (1.29-33).

Realizamos a tradução diretamente a partir do texto grego e, a seguir, cotejamos nosso trabalho com as melhores traduções disponíveis das Diatribes de Epicteto, dando especial atenção às de Georg Long (1890), Oldfather (1928), Dobbin (2006) e de Souilhé (1962).

\section{TRADUÇÃO}

(1) Qual é a razão para assentir a algo ${ }^{1}$ Parecer que é o caso ${ }^{2}$. (2) Com efeito, não é possível assentir ao que parece que não é o caso. Por quê? Porque é a própria natureza do pensamento assentir ${ }^{3}$ às coisas verdadeiras, estar descontente com as falsas, suspender o juízo em relação às não-evidentes ${ }^{4}$. (3) Qual é a prova disso? Sente ${ }^{5}$, se puderes, que é noite. Não é possível. Não sintas que é dia. Não é possível. Sente ou não sintas que as estrelas são em número par. Não é possível. (4) Assim, quando alguém assente ao falso, sabe que ele não desejou assentir ao falso. Pois toda alma é involuntariamente privada da verdade, como diz Platão ${ }^{6},(5)$ mas pareceu àquele o falso ser verdadeiro. Ora, sobre as ações, o que temos aí que seja tal como o verdadeiro e o falso? O conveniente e o que é contrário ao conveniente, o que é vantajoso e o que é desvantajoso, o que me cabe e o que não me cabe, e quantas outras <expressões> semelhantes.

- Não pode alguém pensar que algo é vantajoso para ele e não escolhê-lo?

- Não pode.

\footnotetext{
${ }^{1}$ Quanto a esse parágrafo, consultar D 1.18 .1 ss.

${ }^{2} \mathrm{~A}$ frase é: to phainesthai hoti hyparchei. Temos traduzido phainomai por "afigurar-se" e dokeo por "parecer", sendo ambos os verbos sinônimos em Epicteto. Nesta passagem, porém, por eufonia, invertemos a nossa opção habitual.

${ }^{3}$ Epineuo.

${ }^{4}$ Pros de ta adela epechein. Cf. D 1.7.6.

${ }^{5}$ Aqui, como em D 1.18.1, o verbo é paschein.

${ }^{6}$ Cf. Platão, Protágoras, 345 e ss.; 352 c; 358 c-d; Górgias, 468 c; 509 e ss.; Timeu, 86 d - 87 b; Sofista, 228 c-e; Leis, $731 \mathrm{c}$.
}

Dialektiké, v. 2, 2016. p. 48-54 
- (7) Como Medéia7 diz o seguinte?

Entendo que estou para praticar tais atos criminosos,

Porém, meu coração ${ }^{8}$ é mais forte que meu propósito 9 .

- Por isso mesmo, para agradar ${ }^{10}$ seu coração, pensou ser mais vantajoso punir o marido que manter os filhos a salvo.

- (8) Sim, mas ela se enganou.

- Mostra a ela, de modo claro, que ela se enganou, e ela não fará isso. Enquanto não o fizeres, o que ela tem para seguir senão o que se afigura? Nada. (9) Então por que te irritas com ela? Porque a infeliz se enganou sobre as melhores coisas e se fez víbora no lugar de ser humano? Por que antes não tens pena dela? Do mesmo modo que temos pena dos cegos e dos mancos, <por que> também não temos pena dos que estão cegos e mancos em relação às coisas mais importantes ${ }^{11}$ ?

(10) Assim, quem quer que se lembre disto claramente, que, para o ser humano, a medida de toda ação é o que se afigura ${ }^{12}$ (de resto, ou bem se lhe afigura ou mal; se bem, é irreprochável ${ }^{13}$; se mal, é penalizado; pois não pode ser um o que se engana e outro o que sofre o dano), não ficará irado, não se irritará com ninguém, não ofenderá, não censurará, não odiará ninguém, não se ofenderá com ninguém ninguém.

- (11) E também essas momentosas e terríveis ações têm o mesmo princípio, o que se afigura?

- Esse e nenhum outro. (12) A llíada nada é senão a representação e o uso das representações. Pareceu bom ${ }^{14}$ a Alexandre abduzir a mulher de Menelau. Pareceu bom a Helena seguir Alexandre. (13) Desse modo, se parecesse a Menelau um ganho ser privado de

\footnotetext{
${ }^{7}$ Os versos abaixo são da Medéia, de Eurípides (versos 1078 e 1079). Como observa Georg Long, em 1079, ao invés do dran mello, que aparece em Epicteto (bem como em outros autores antigos), temos, no texto atualmente estabelecido, tolmeso (Upton).

${ }^{8}$ Thymos: literalmente "sede da raiva, das paixões".

9Boulema. O termo, em Eurípides, é vertido ora por "minha razão" (Souilhé), ora por "purposes" (Dobbin), ora por "better consel" (Georg Long e Oldfather). Nossa opção decorre de nossa tradução do termo em Epicteto, que ocorre em D.17.14; 15;17 e que traduzimos por "propósito".

${ }^{10} \mathrm{O}$ verbo aqui é charizo.

${ }^{11}$ Como observamos acima, para Epicteto, o sentimento de pena é contra a natureza, sendo, porém preferível ao ódio. Cf. D 1.18.10: "Homem, se te é preciso se dispor contra a natureza por males de outrem, antes tem pena dele que ódio".

12 Hoti anthropoi metron pases praxeos to phainomenon. Comparar com a tese do relativismo afirmada de Protágoras, mencionada por Platão, no Teeteto $(160 \mathrm{~d})$ : “O homem é a medida de todas as coisas" (panton chrematon anthropon metron einai).

${ }^{13}$ Anenkletos.

${ }^{14}$ Ephane: terceira do singular do aoristo de phainomai ("afigurar-se"), sinônimo de dokeo ("parecer") em Epicteto. Aqui, tanto por eufonia quanto por clareza, traduzimos ephane por "pareceu bom que".
} 
tal mulher, o que aconteceria? Perder-se-ia não só a llíada, mas também a Odisséia!

- (14) Então essas momentosas coisas dependem das pequenas?

- E dizes ainda que elas são momentosas? As guerras, as disputas políticas, as perdas de muitos seres humanos, a demolição de cidades? O que há de grande nisso? Nada. (15) E o que há de grande na morte de muitas cabeças de gado e muitos carneiros, e no incêndio e na destruição de muitos ninhos de andorinhas ou de cegonhas?

- Mas estas coisas são semelhantes àquelas?

- Muito semelhantes. São aniquilados os corpos dos seres humanos, assim como o das cabeças de gado e dos carneiros. São incendiados os diminutos lares ${ }^{15}$ dos seres humanos, bem como os ninhos das cegonhas. (17) O que há aí de grande ou terrível? Ou mostra-me em que difere a casa ${ }^{16}$ do ser humano e o ninho da cegonha enquanto habitação ${ }^{17}$.

- (18) Então a cegonha é semelhante ao homem?

- Que dizes? Muito semelhante quanto ao corpo, exceto que <o ser humano> constrói suas diminutas casas ${ }^{18}$ com vigas, telhas e tijolos, enquanto a <cegonha constrói seus ninhos> com galhos e argila.

- (19) Porém, em nada difere o ser humano da cegonha?

- Claro que sim! Mas nessas coisas não difere.

- No que, pois, difere?

- (20) Busca e descobrirás que difere em outra coisa. Não vês que <o ser humano difere da cegonha> por compreender o que faz, por ser sociável ${ }^{19}$, por ser $\left|{ }^{2}\right|^{20}{ }^{20}$, por ser digno $^{21}$, por ser inteligente ${ }^{22}$ ? (21) Então onde está o grande mal e o grande bem nos seres humanos? Onde a diferença está. Se <o ser humano> conservar e perseverar fortificando isso e não destruir seu <caráter> digno, leal, sua inteligência, também conservará a si mesmo. Entretanto, se alguma dessas <qualidades> for aniquilada e sitiada ${ }^{23}$, também o ser humano será aniquilado.

(22) E as grandes coisas estão nisso. Alexandre, como dizem, deu um passo em falso ${ }^{24}$ quando os gregos atacaram e pilharam Tróia e seus irmãos pereceram? (23) De modo

\footnotetext{
${ }^{15}$ Oikemation: diminutivo de oikema (“Iar", "casa”).

${ }^{16}$ Oikia.

${ }^{17}$ Oikesis.

${ }^{18}$ Oikidia: acusativo plural de oikidion, diminutivo de oikia ("casa").

${ }^{19}$ Koinonikos.

${ }^{20}$ Pistos.

${ }^{21}$ Aidemon.

${ }^{22}$ Synetos.

${ }^{23} \mathrm{O}$ verbo aqui é ekpoliorkeo, que significa literalmente "forçar uma cidade à rendição através de um cerco".

${ }^{24} \mathrm{O}$ verbo aqui é ptaio, que significa literalmente "tropeçar", donde também "dar um passo em falso", "cometer um erro".
} 
algum. Pois ninguém dá um passo em falso por obra de outrem: essa é a destruição dos ninhos das cegonhas. Mas o passo em falso ${ }^{25}$ <ocorreu> quando aniquilou <seu carácter> digno, leal, hospitaleiro ${ }^{26}$, harmônico ${ }^{27}$. (24) Quando Aquiles deu um passo em falso? Quando Pátroclo morreu? Absolutamente não! Mas quando ficou irado, quando chorou por uma mocinha ${ }^{28}$, quando se esqueceu de que lá estava não para adquirir amantes, mas para guerrear. (25) Estes são os passos em falso humanos, isto é estar sitiado ${ }^{29}$, esta é a demolição: quando as opiniões retas são demolidas, quando são destruídas.

- (26) Então, quando as mulheres são levadas, as crianças aprisionadas e os próprios homens chacinados - essas coisas não são más?

- Como acrescentaste essa opinião? Ensina-me.

- (27) Não. Como tu dizes, porém, que essas coisas não são más?

- (28) Vamos às regras. Mostra as pré-noções.

Pois por isso não ocorre muito admirar o que acontece ${ }^{30}$. Onde queremos julgar pesos, não julgamos ao acaso. Onde <queremos julgar> as coisas retas e as tortas, não <julgamos> ao acaso. (29) Em suma: onde faz diferença para nós saber o verdadeiro em um caso particular, nenhum de nós age ao acaso. (30) Contudo, quando a principal e única razão é agir corretamente ou cometer faltas, < ter uma vida $>$ com curso sereno ou caudaloso ${ }^{31}$, ser desafortunado ou bem-afortunado, aí somente <agimos> ao acaso e escorregamos. Em parte alguma algo semelhante a uma balança, a uma regra, mas algo parece bom ${ }^{32} \mathrm{e}$ imediatamente sigo o que parece bom. (31) Sou, pois, melhor que Agamenon e Aquiles porque eles, por seguirem as coisas que se afiguram ${ }^{33}$, fazem e sofrem tais coisas más? A $\operatorname{mim}<$ também> não basta o que se afigura ${ }^{34}$ (32) E que outro princípio há para a tragédia?

\footnotetext{
${ }^{25}$ Ptaisma.

${ }^{26}$ Philoxenos.

${ }^{27}$ Kosmios.

${ }^{28}$ Korasidion.

${ }^{29}$ Poliorkia.
}

${ }^{30} \mathrm{~A}$ frase é de difícil tradução. Souilhé a verte como: "Voici purquoi on ne peut s'étonner assez de la façon d'agir habituelle"; Dobbin, "And this is why I cannot be sufficiently astonished at what goes on" e Georg Long, "For it is because this is neglected that we can not sufficiently wonder at what men do". A tradução literal é: "Pois (gar) por isto (dia touto) não há suficiente (ouk esti ikanos) admirar (thaumasai) o que ocorre (to ginomenon)". O sentido parece-nos ser: "Pela seguinte razão não se admira as coisas que ocorrem o suficiente <para se perder o caráter digno, leal, atc.>".

${ }^{31}$ Temos aqui os verbos euroeo ("bem fluir") e dysroeo ("mal fluir") se opondo. Epicteto utiliza o termo euroia para designar uma mente "que flui bem", isto é, que é serena (Cf. E. 8).

${ }^{32} \mathrm{Cf}$. nota acima a D 1.28.12.

${ }^{33}$ Tois phainomenois: dativo plural de phainomenon.

${ }^{34}$ Aqui Schweighäuser sugere retirar o "não" ( $m e$ ) na segunda frase. Entretanto, Dobbin o mantém, chegando à seguinte tradução: "Am I better than Agamemnon and Achilles, in that they do and suffer such wrongs because they follow their impressions, while I am not content to follow my own?"; Georg Long faz o mesmo: "Must I then suppose that I am superior to Achilles or Agamemnon, so that they by following appearances do and suffer so many evils: and shall not the appearance be sufficient for me?" Souilhé, porém, segue Schweighäuser. Mas parece-nos que Oldfather, aqui, acertou, ao traduzir assim a passagem: "Must I then suppose that I am superior to Achilles or Agamemnon, so that they by following appearances do and suffer so many evils: and 
Qual é o princípio do Atreu de Eurípedes? O que se afigura. Do Édipo de Sófocles? O que se afigura. Da Fênix? O que se afigura. De Hipólito ${ }^{35}$ ? 0 que se afigura. (33) Então para vós o que parece ser feito de quem nenhum cuidado tem em relação a isso? Do que são chamados todos os que seguem o que se afigura?

- De loucos.

- E nós fazemos outra coisa?

\section{REFERÊNCIAS}

DINUCCI, A.; JULIEN, A. O Encheiridion de Epicteto. Coimbra: Imprensa de Coimbra, 2014.

DINUCCI, A. Fragmentos menores de Caio Musônio Rufo; Gaius Musonius Rufus Fragmenta Minora. IN: Trans/Form/Ação vol.35 n.3 Marília, 2012.

Diatribes 12 e 13 de Musônio Rufo: Sobre coisas relativas a Afrodite e casamento.

IN: Revista Crítica Histórica, v. 7, p. 348, 2013. Disponível em:

http://www.revista.ufal.br/criticahistorica/index.php?option=com_content\&view=article\&id $=178$ : diatribes12e13demusoniorufo\&catid=87: documentacao\&Itemid=63

Apresentação e tradução da Diatribe 1.1 de Epicteto. IN: Revista ARCHAI. As origens do pensamento ocidental, v. 13, p. 143-157, 2014. Disponível em:

http://seer.bce.unb.br/index.php/archai/article/view/11000

Apresentação e tradução da Diatribe de Epicteto 1.8. IN: Prometeus. Filosofia em Revista, v. 7, p. 289-295, 2014. Disponível em:

http://seer.ufs.br/index.php/prometeus/article/view/2845

Tradução e comentário à Diatribe de Epicteto 1.2: como manter o caráter próprio em todas as ocasiões. IN: Veredas da História, v. 5, p. 197-208, 2012. Disponível em: http://veredasdahistoria.kea.kinghost.net/edicao8/15_TRADUCAO_COMENTADA_197208.pdf

Introdução ao Manual de Epicteto. 3 ed. São Cristóvão: EdiUFS, 2012.

DINUCCI, A. L.; BRITO, R. P. Tradução e Apresentação da Diatribe de Epicteto 1.5. IN: Revista de Filosofia Antiga (USP. Ed. português), v. 8, p. 116, 2014. Disponível em:

shall not the appearance be sufficient for me?" Pois é pouco provável que Epicteto pudesse se declarar melhor que quem quer que seja em vista de sua profissão de ignorância (cf. D 1.9.15), além do que, na passagem em questão, ele deve estar fazendo com que o aluno reflita não ser melhor que os personagens trágicos, por seguir também, como guia para as suas ações, o que parece bom ou o que se figura como sendo o caso. Tal interpretação é confirmada pelo que Epicteto diz ao final da diatribe.

${ }^{35}$ Tragédia de Eurípedes.

Dialektiké, v. 2, 2016. p. 48-54 
http://www.revistas.usp.br/filosofiaantiga/article/view/81223/pdf_12

DIÓGENES LAÉRCIO. Lives of Eminent Philosophers, vol. I, II. Trad. R. D. Hicks. Harvard: Loeb Classical Library, 1925.

EPICTETO. Entretiens. Livre I. Trad. Joseph Souilhé. Paris: Les Belles Lettres, 1956.

Epictetus Discourses book I. Trad. Dobbin. Oxford: Clarendon, 2008.

O Encheirídion de Epicteto. Edição Bilíngue. Trad. Aldo Dinucci; Alfredo Julien. São Cristóvão: EdiuFS, 2012.

Testemunhos e Fragmentos. Trad. Aldo Dinucci; Alfredo Julien. São Cristóvão:

EdiUFS, 2008.

EPICTETUS. The Discourses of Epictetus as reported by Arrian; Fragments; Encheiridion. Trad. Oldfather. Harvard: Loeb, 1928.

HORÁCIO. Satires, Epistles, Ars Poetica. Trad. H. R. Fairclough. Harvard: Loeb, 1926.

LONG, Georg. Discourses of Epictetus, with Encheiridion and fragments. Londres: Georg Bell and sons, 1890. 